\title{
Blockchain-based Ubiquitous Learning Method towards Higher Education security
}

\author{
Miftahul Akhyar ${ }^{1}$, Tubagus Muhammad Fadla Yoga ${ }^{2}$, Eva sukmawati ${ }^{3}$ \\ University Of Raharja ${ }^{1,2,3}$ \\ Jl. Jenderal Sudirman No.40, RT.002/RW.006, Cikokol, Kec. Tangerang, Kota Tangerang, \\ Banten 15117,2,3 \\ e-mail: akhyar@raharja.info ${ }^{1}$, tubagus.muhammad@raharja.info ${ }^{2}$, \\ eva.sukmawati@raharia.info ${ }^{3}$
}

Akhyar, M., Fadla,Y.M.T., Sukmawati,E.,

Blockchain-based Ubiquitous Learning Method towards Higher Education security Blockchain Frontier Technology (B-Front), 1(2), 44-54.

DOI : https://journal.pandawan.id/b-front/article/view/53

\begin{abstract}
In the last fifteen years, the acceleration of technology and information has been accelerating from year to year. Along with the ongoing digitalization, which brings different problems, issues that often arise regarding the preparation of the current workforce are moving towards further education. In this preparation, pragmatic and hypothetical information can emerge from various containers, mean and channels, whether formal or causal. In addition, it is very difficult to evaluate the level of information skills that students acquire in order to increase their chances of finding jobs in the future. This, along with the need to oversee general education programs, the issue of certainty when approving these files and distinguishing them from original information, and so on, implies that administration in further education needs new, progressive instruments. This work assesses the advantages of blockchain innovation (or delivered notes) and supports a decentralized certainty model for blockchain ubiquitous deployments. In this methodology, blockchain is used to oversee transactions of substance, education and abilities, evaluated with the approval of students, mentors and businesses, to remove for the last time the "gap" between academia and the world of work. This paper intends to address the pervasive, open and ubiquitous current challenges of continuing education. The proposed model can be implemented in any preparatory organization to tailor instructions to the specific needs of an expert profile approved by superiors at the second summit. This model is approved by the method for models with results that more than just acknowledge.
\end{abstract}

Keywords: Blockchain, Competencies, Mined consensus, Digital certificate, P2P Confidence

\section{Introduction}

The type of continuing education that is running today is increasingly decentralized, diverse and difficult to examine and approve, a wide variety of problems that result in any agency's action plan including being adept at preparing to be remembered for the world of work, especially mentoring (managed or something else), substitute, and boss. It is increasingly common for students that the training received does not only come from universities, but also to take part in massive online open courses (MOOCs), direct or distant meetings. Exercises learned from videos, video chats or interviews, and so on.

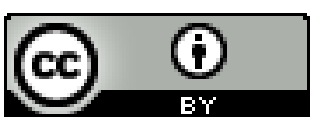

Copyright (c) Akhyar, M., Fadla,Y.M.T., Sukmawati,E., (Author).This work is licensed under a Creative Commons Attribution 4.0 
The origin of this information, as well as the implementation of the expert himself, speaks to the broad range of results that enable students to acquire skills that can be used as they enter the world of work and expertise.

However, it is difficult to measure, survey, and agree on this information if it does not come from managed considerations that depend on many organizations to focus on. What's more, regardless of whether it comes from focused research, the plans for each schedule fluctuate in such a way that students are forced to collect a wide variety of notes were made, such as taking placement tests and conducting meetings of various kinds, to demonstrate his ability and grade attained.

From a tertiary perspective, there is a broad employability analysis, coupled with the way that an advanced degree cannot adjust quickly and deftly to job market requirements that prepare for satisfying "opportunities to advertise". There is considerable leeway. long since the planning of a four-year tertiary education or the design of an education plan with the aim that its first alumni can demonstrate $t$ he suitability of their preparation through skillful efforts. Also, focus organizations and bodies confirming education programs continue to initiate extended evaluation measures that neglect to recognize preparation problems as expected, or to increase the capacity of colleges to adapt in a comfortable way to work in real factor markets.

From the entrepreneur's point of view, there are additional issues. The proliferation of data in society makes it difficult to improve the way staff are recruited or collect their CVs, making it difficult to know which graduates are more ready for work. There is also extortion, fraud, and chaos are commonplace as any organization wishing to utilize a certified expert often needs to collect a heterogeneous and missing measure of documentation from new entrants, check its validity and, ultimately, decide If competencies are being affirmed by students it ends up being a valuable competency for dealing with genuine problems in the expert profile sought.

This research presents the use of blockchain innovations (mostly known for their use in consensual, secure, decentralized and inseparable registration of cryptocurrency exchanges, for example, Bitcoin) in the field of open and universal further education, noting obtaining information and approving it by incorporating it into the original problem. adjusted to business settings.

Q1 Evaluation in existing training institutions based on reputation capital which results in objective and unusual procedures. This achievement depends on the results of the student's performance in the professional training of the directions given to the assignments, so as to quickly identify which training source is superior and which is worse to get the results of the professional comparison.

Q2 Their teaching based on the needs of the job market can be adapted to the training institution, can improve their internal quality and quality, and can immediately tell whether their students can achieve professional success, and not long after successfully completing a course, course or workshop.

Q3 Paper-based reports issued by executives for capabilities, CVs, courses, and accreditation, as well as possible misstatements or deviations from these records

Q4 Students can get a complete, digital, valid and easily verified educational history by anyone because it is updated, making documentation work easier and more. easy to access to work. What's more, it comes with components for determining which foundation best suits their needs, including the college to which it is directed, as well as various preparatory assets or information assets scattered on the Internet that ensure their education with value. further testament

Q5 Employers have their own procedures for coordinating the preparation of students' professional profiles, in an active, proactive and efficient manner, where all abilities are no longer required for re-testing, information and abilities of applicants.

\section{Related jobs and existing innovations}

\subsection{Blockchain technology}

Blockchain alludes to PC innovations that enable decentralized and delivered capacities from advanced exchange records. Its first execution took place in 2009 , in connection with the main advanced cashier Bitcoin and its creators taking cover behind the alias Nakamoto. It is an 
unpredictable innovation, with great potential, whose main characteristic and potential is the presence of a world without, or almost without, an intermediary. The problem is that this understanding of non-intermediaries oscillates between two posts with similar levels of uncertainty: a world without intermediaries that all depend on some focus of strength, to be precise "Up To Down", U2D, or a world of power and equity, particularly "Shared.", P2P.

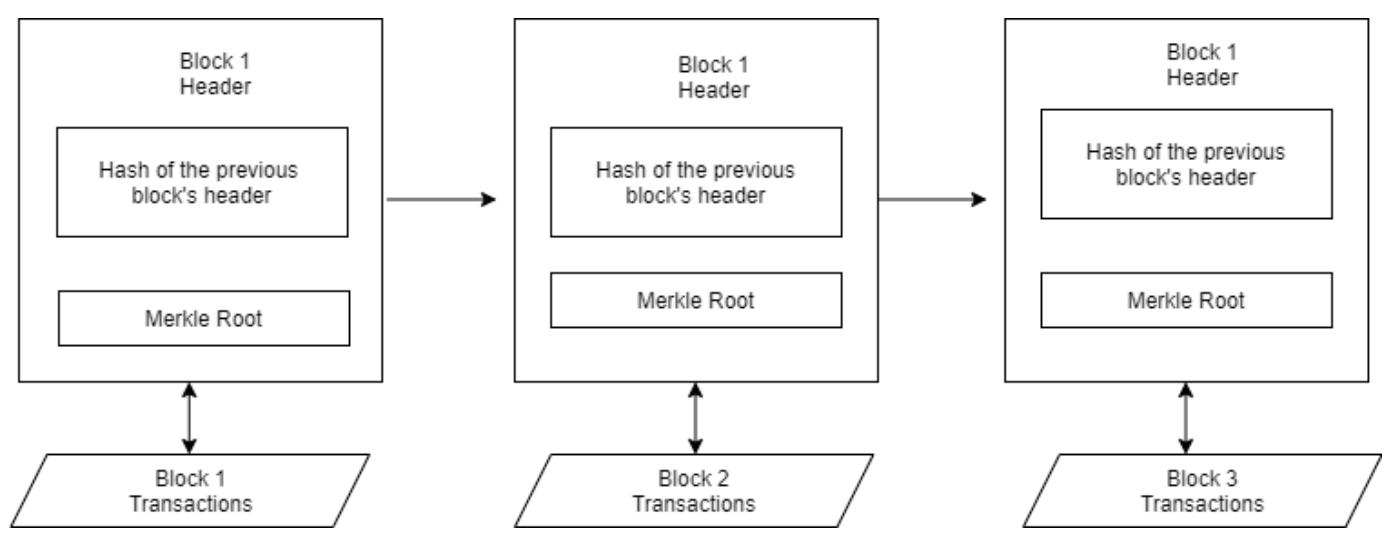

Figure 1. Blockchain general structure

As shown in Figure 1, the Blockchain structure is an overview of the connected and requested exchange boxes, each differentiated by a hash job (fixed length numeric advanced outline). The hash of each exchange is registered via a multi-step measure that includes, in doing so, checking for different hashes until one last hash, known as the Merkle root, is generated. Additionally, each box stores the hash of the header of the previous box, this way connecting the two boxes. This keeps the grid immutable without needing to adjust each resulting block. Exchanges are also identified with each other.

Blockchain is supervised in collaboration by all individuals from the organization and requires confirmation that a lot of important work has been put into the creation of each box (Proof of Work, POW). This is done to ensure that malicious clients who try to customize the previous box are forced to do a lot of work, more than legitimate clients who just need to add another box. Since a square hinges on the preceding box, it doesn't make sense to expect to change a particular square without adjusting each subsequent box. This results in the cost of adjusting the squares increasing with each new square added [10].

The test job calculations used take advantage of the seemingly irregular nature of the hash. To demonstrate that work has finished adding another box, the hash must be generated from the box header that does not exceed a certain value. In addition to the claimed Altcoins (a Bitcoin product fork to characterize the new "elective" digital currency) there are elective uses of the blockchain. This is not necessarily just cryptocurrency. This execution, which is called Altchains, consists of the calculation of the deal and the corresponding "logbook" as a stage for contracts, name registration, etc. Altchain uses the same basic boxes and sometimes coins or tokens as the method for installments, but the main ones. designs are not to be used as money.

Ultimately, Alt Chains, as its name indicates, is an elective Blockchain execution, the fundamental reason for its existence is not to be used as money. Although many insert coins, they use them as "tokens" to store important or significant substances, for example, agreements or assets. Ethereum is another important model, as it is an agreement preparing and execution framework that depends on the blockchain.

Ethereum uses the total Turing language, and has its own cash, called Ether, which is used during execution hours. Additionally, Ethereum can embody a confusing framework that is Altcoin. In this way, Ethereum is the stage for building Altcoins. Bitcoin and Altcoins can take advantage of bitcoin's fame by using a similar PoW system. Correspondingly, the 
excavator (the center of the organization entrusted with conducting PoW) can earn several coins for the cost of one. In order to use this procedure, Altcoins must be viable with combined mining. It uses the space accessible from Bitcoin exchange contributions by storing Altcoin data. Transactions are the inspiration and fundamental purpose behind Blockchain based execution.

Various pieces of work to ensure that exchanges are properly created, assigned to the organization (P2P), checked and added to the Blockchain. An exchange is an information structure that holds the exchange of "significant value" between members of the framework. Each exchange is stored as a contribution on the Blockchain. Since this innovation has possible uses in the past for its unique reasons for making installments, some designers have used Blockchain for various applications, for example, public accounting, agreements, and preparation, among others.

\section{Blockchain related businesses in terms of: Blockcert and Edgecoin}

After clarifying Blockchain innovation, it should be noted that it has been implemented in various fields, including schools. Until now, there has been no use of Blockchain innovation and mining capabilities, for example, in support of that presented in this paper, which will empower all the problems described in the field of introduction to support. Over the years, MIT has made advanced authentication, as opposed to paper, for certain courses, classes and workshops it was founded when it was founded. This digital declaration has the benefit of being firmly affirmed by the University that published it, so that it cannot adapt and cannot be changed, stored in the Blockchain created for this reason.

Correspondingly, scholastic certification is kept in an irreversible chain, as in this proposition, but for this situation complete capabilities are excluded, which have not yet been embraced or approved by biological systems to which they are legitimate. Therefore, it is possible for students to have computerized versions of their abilities that cannot be adulterated and usable to use, but the applied information arises because these abilities are not approved in any capacity, or is it possible for areas in whatever capacity the nature of education first, there will also not be a system for surveying itself the employability rate or missing the alumni of the administrative instruments of exceptional and extraordinary quality available.

This advanced model certificate, which combines among the benefits of the proposed model (along with many others), apart from, has tremendous institutional assistance and recognition, to the extent that different Universities have now accepted it, much like private institutions to confirm the capabilities that arise due to their own instructional classrooms. The Institute for the Future (IFTF) and the ACT Foundation introduced what is called "The Ledger" as another innovation that could link learning with income. The activity "Learning is Earning" was introduced as a game that showed a window to the future, 2026 to be precise, where Edublock was used, a kind of computerized money to evaluate the clocks displayed as exchanges and had the option to store them on the Blockchain. For this situation, the methodology is something that goes against Blockchart, as what is saved is not the qualifications but the hours spent in class near and private or far. However, by and by, it does not serve to record capacities or abilities, or to approve them or use them as computerized educational plans for managers.

Then, the Edge Coin project seeks to establish certain Cryptocurrencies, in Bitcoin's view, to manage the market for products and businesses identified with the field of education, for example, enrollment in online courses, miniature agreements between preparation companies, and computerized exchange of monetary resources to acquire books, uphold benefit, or controlled investigation. This methodology only uses an alternative part of Bitcoin to control the computerized market in the area, without managing in any capacity with the teaching field itself, exchanging skills and learning outcomes or capacities, crypto approvals and guidelines from it.

\section{Study Literature Ubiquitous}

Literature study is a method that is often used in seeking information and references from various sources from scientific journals, literature, books and opinions from experts 
who have common topics that are included in ongoing research. The purpose of the literature study is to understand information from various references to the results of previous research, so that it can be proposed to carry out further research activities. In this study, there are 5 (five) literature reviews about similar studies: Research conducted in 2020 with the title "Characteristics of Blockchain Technology in Educational Development", this research describes the combination of the field of education and blockchain technology that will create a new revolution in the education industry. The existence of a lighthouse about Blockchain technology is often cited as one of the revolutionary solutions to educational polemics so far. The combination of the field of education and blockchain technology will create a new revolution in the education industry.

Similar research conducted in 2020 by S. Kosasi with the title "Characteristics of Blockchain Technology in Educational Development" in the research conducted, including discussing the existence of a lighthouse about Blockchain technology, often referred to as one of the revolutionary solutions of educational polemics so far. The combination of the field of education and blockchain technology will create a new revolution in the education industry. Therefore this research can also be the basis for the platform and characteristics of the new blockchain as the forerunner of blockchain technology-based government.

In the year a study was conducted entitled "Benefits of lot Technology Applications in the Covid-19 Pandemic: Exploratory Study" in which the research article discusses IoT which allows promising results and the potential to identify cases of Covid19, eliminate the spread, and reduce the impact of the pandemic on the field education, business and health. Similar research has also been carried out by Muhammad Rizka, Waskitho Wibisono, Tohari Ahmad with the title "Improving Multi-Agent System Performance by Optimizing Load Allocation (Case Study of Data Encryption with AES Algorithm)" The results of this research show that the proposed method can improve performance. multi agent system in carrying out the job encryption process up to $30.99 \%$ compared to Uniform Distribution (DU)

Implementation of Secure Multi-Party Computation Using the Shamir Secret Sharing Method on Securing Secret Digital Documents is an interesting study conducted by Willy Sudiarto Raharjo, Antonius Rachmat C, Pedro Nadirio A in 2018. This research talks about the outline of defeating the issue of respect for unpredictable information. completed by Shamir's Secret Sharing, specifically using the Hashed Key.

\section{Certainty model dependent on Blockchain, competencies-effort tests and "praise"}

The execution at Ethereum expects to offer shape to the proposed Blockchain-based trust model to confirm the safeguarding of competence through an introduction consisting of standard issue settings whose prize is Kudos.

Figure 2 is combined to illustrate the thinking behind the proposed model. It should be noted that there are several meetings that have benefited from it

a. Mentor. An organization that educates students to secure certain abilities. For the position of a mentor, it is important that students who are notified in a competency demonstrate that they have it. Despite the fact that in the current worldview, foundation preparation has confirmed the skills acquired by their students, this examination is more formalistic than successful, therefore a more sensible methodology is required as described here.

b. Student. Individuals who have been notified by a mentor in a competency. Understudies really wants this competency to be accepted by individuals who are experts in it (verifier) so that in this way they have confidence in relation to their acceptance in the job market.

c. Verifier. Individuals, students and experts (numeracy educators), are prepared to evaluate the acquisition of a competency by students. Inspectors, obviously, must continually demonstrate their ability within the capabilities to be surveyed, which firmly influences their position on mentors and managers.

d. Employer. They are interested in knowing the abilities each member has in order to 
have the option of enrolling staff for their organization in an appropriate manner. Business only advises the chain, and does not characterize fitness in today's worldview (other authority organizations do); However, their cooperation on speculative changes in view seems to be helpful for better regulation of market needs related capabilities.

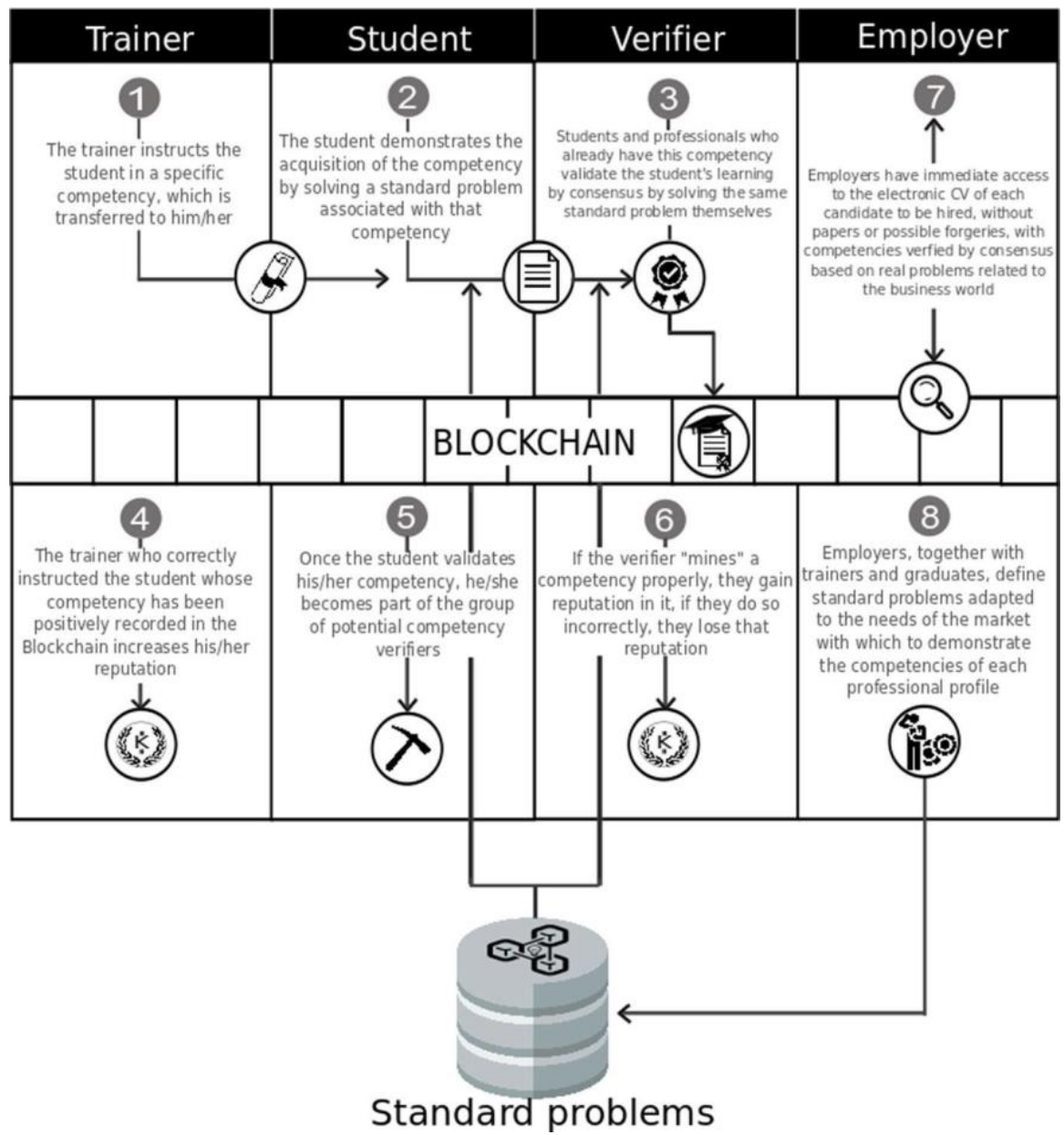

Figure 2. Main components of the proposed model

As can be found in Figure 2, framework-related encounters are associated with Blockchain as the main issue in which framework exchanges are stored. For casual use situations, it all starts when a trainer trains a substitute so that the person gains certain competencies which are transferred to that person. Then students need these competencies to be perceived. With the current world view of training, adequate ability or support, indeed, does not fill as conclusive evidence of student gaining competence. With the proposed model, understudies should exhibit the securing of competencies by paying attention to the standard problems associated with these competencies. Standard problems, which will be discussed later, are kept on file and resolved by specialists in each competency.

When the coating has dealt with a standard problem, the examiner, who is required to have the competence to be surveyed (there will be an exchange in the chain indicating this), will also discuss, as a verification of deployment, the very standard problems that have been presented to students by the framework, and may not approach the arrangement given by students until they decide for themselves to see the results obtained. To be honest, this is 
a mining cycle in the proposed model, which is a reasonable type of mining, which consists of standard problem setting and checking of results obtained by students and verifiers. If the examiner reaches an agreement that the "newcomer" has dealt with the standard problem effectively, the exchange will be agreed within a framework that allows the provision of student competencies (Fig. 2-stage 3). If there is no agreement, both students and the foundation are prepared to lose their reputation regarding the competencies being evaluated.

\section{Results and Discussion}

With the algorithms, systems and technology described in the previous section, which aims to respond to the following working hypothesis:

- RQ1: This model allows to compare training institutions involved in teaching students in the same professional competences, identifying institutions with training malpractices.

- RQ2: This model allows to support students' knowledge, identify students who lack a minimum knowledge, as a source of quick and simple information for employers.

- RQ3: this model allows to recycle regulated and unregulated teaching to suit the business situation.

The validation experiment involved 4 training institutions, whose names were omitted to avoid collusion or bias in research: Open University with two courses, the MOOC cycle, studies administered by multinational technology academics and certified online nonplatform courses with decreased prestige. For each institution, 20 students enrolled, who successfully completed their practice satisfactorily, without bias in terms of age, gender, professional occupation or previous studies / knowledge, bringing together a total of 80 students who passed the course (20 students who passed two university subjects simultaneously, 20 from the MOOC, 20 from the academy and 20 from the non-certification platform).

Likewise, there are 2 registered user organizations, whose names are also banned, one concentration in consent analysis including 4 preparatory foundations, whose names are excluded to avoid conspiracy or inclination in exploration: Open University with two courses, MOOC cycle, overseeing concentration by innovation scholastics global and confirms nonstage online courses with declining excellence. For each organization, 20 students enrolled, effectively completing their preparation well, regardless of age, sexual orientation, good work or previous examinations / information, bringing together a total of 80 students who passed the course (20 students who moved from two courses all at once, 20 from the MOOC, 20 from the institute and 20 from the non-confirmation stage) in Network Administration, and another in Database Administration.

In addition, there are a total of 100 verifiers, or "diggers", from the academic community (Raharja University qualified alumni) and more than $40 \%$ of the world's experts in the field, plus clearly approved expertise in this area of expertise. For testing, the Ethereum blockchain is prepared for log reports, reports, and an XML social information base for standard issue creation and use. First of all, bosses are encouraged to provide standardized issues that allow inferred competencies to be checked in the expert profile zone to be considered. Following half a year of activity, students gain the abilities described by each mentor. As indicated in the investigation, 80 students were deemed to have passed their entire exam, and were approved by the mining, Blockchain stockpiling, and notoriety evaluations of each of the organizations that were included. The test results are summarized in the attached area.

- Rq1

Based on the educational institution, out of a total of 80 students who have received technical competencies, only 58 have successfully validated this competency by addressing 
standard problems set by the user elements mined with certainty through the understanding of the verifiers. 58 of these abilities are fed into the Blockchain, leaving different students (22) outside the approved competency record (they may fail by the related preparation foundation). A definite report led by the specialist board of materials manufacturers and bosses confirmed that the preparatory organization in fourth place did not prepare students well, although it certainly showed that they would gain that ability, given their technique. , indicated staff and their content, they can not send. For different foundations, boards pretty much agree that they are similar in terms of preparation, perhaps presenting the first-placed organization as the highest. Table 2 shows the results.

- Rq2

Prospective employee meetings, access tests and investigations were directed with each of the 80 students by a specialist board of the utilizing organization. In this test, the mining yield was approved by $98.75 \%$, which clearly acknowledged that 22 people lacked the skills necessary to handle day-to-day tasks that could not be removed in the expert profile in question. Of the 58 students who won about their skills, 1 ended up being unsuitable for the job. This case examined, through controlled review, found that students replicated from different students in the sample during standard critical thinking measures. This very important reality will be examined at a later date.

- Rq3

To achieve convincing results for this speculation of work will require direct and indirect perceptions of the use of this model in further education in a large number of organizations of various types, to check its recognition and weight in the planning of future directed educational programs. . In order to achieve uncertain subjective results that provide answers to questions, contextual inquiry, in meetings led using the Delphi technique, with a board consisting of educators directly engaged with the use of the proposed model. A total of 12 educators took interest from exam-related preparation foundations, 2 gave classes at the University, 3 gave classes in the MOOC cycle, 5 at the Technology Academy, and 2 in online courses. Initially, not all of them are given the results achieved in the mining cycle of their students, and the weighting of the organization they are in, until the meeting is over.

1. Do they think this model is ideal for adjusting further education to the real factors of business. The results, in a closed yes / no overview, are shown in Figs. 6. There is no true agent relationship between the reactions and the formation of the preparations in which the respondents were found

2. Only one instructor from an innovation institute was examined for dissent, given that despite the fact that it is a very potential and proficient model, there are certain parts of the preparation that may differ from business because it is simply the organization (in this respondent's study an assessment) that underpinning it explicitly provides for the preparation of its workers in its own HR preparation program.

3. If more than $10 \%$ of your students fail to validate the competency results they have gone through with your training, have you thought about combining your strategy and content? The results, on a Likert 5 price scale, are shown in Figure 3. 


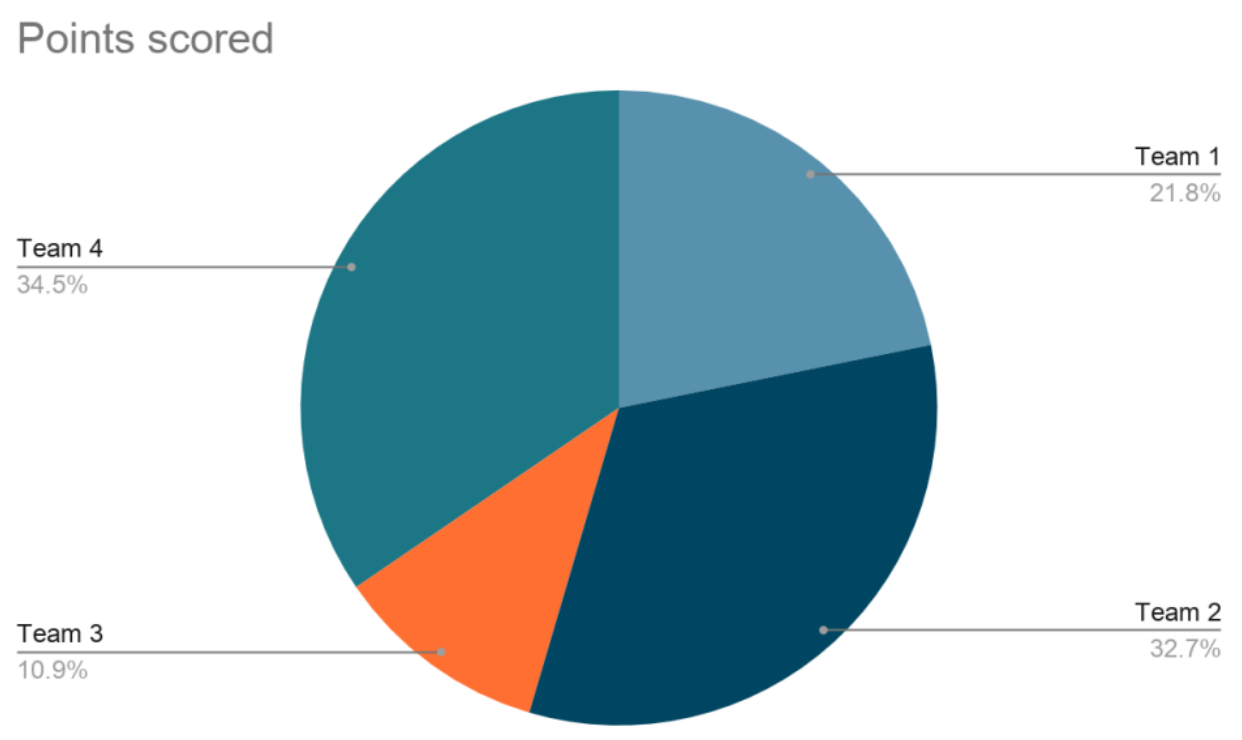

Figure 3. Board Reaction

This section illustrates that there are disparities based on the stance in which each respondent is found, and thus this figure shows the beginning. After the main conference, the board is faced with a second exploratory meeting to find the explanation behind each educator's answer. At the University, 2 educators firmly agree with this statement. Due to the MOOC cycle, 2 instructors fully agreed and 1 did not show this value because he did not consider it important if the drive system was to be changed, but only the substance. As for the innovation foundation, instructors who thought it was useless to change the substance into business reality gave an impartial reaction, other educators indicated that they agreed to change the substance but not the strategy, the last 3 educators (more than half) stated that they fully agreed with the statement.

Finally, Internet instructional training instructors spoke in an unexpected way: one impact agreed to change their technique, but not their course content because they thought it appropriate. Others stated that they were deviant, considering that their non-formal instruction should not depend on the informed consent of students and that this change would only affect the company being managed. However, this statement clearly omits notification of instructional training and their costs, which can be criticized if graduates do not secure guaranteed capabilities. In summary, it is important to underline that of the 12 studied, 7 (nearly 60\%) agreed to change their teaching system if students raised competency issues expressed gratitude for the covenant trust proposed here, and 10 (over $83 \%$ ) would consider, how similarly, adapt the materials or techniques used. In addition, more than $90 \%$ consider this model ideal for matching further education to the real factors of business.

\section{Conclusion}

The research undertaken presents an open and ubiquitous model of trust in higher education, in view of Blockchain innovation, which confirms the procurement of competencies by students prepared in various educational foundations. The proposed model hinges on the consensus of specialists essential to the actual framework. The advantage that can be taken from the hidden innovation approach itself and addresses a serious step forward in teaching, as it allows strong confirmation of acquiring abilities by students, and also, ensures that their preparation is appropriate for the actual work circumstances and current market needs. Also, it allows the preparatory organization's 
estimates related to this cycle to be evaluated fairly, consequently, and decentralized. It is possible for these elements to have a quick and viable component to surveying their own education and adjusting to the changing job market. It also improves the way to register and inspect upcoming businesses that, while not worried about archival forgery, will be removed. In conclusion, students will appreciate a totally open, fearless, computerized education plan approved by a capable local area.

This model has emerged as a truly useful use model, surveyed in native climates, and has positive results showing the endless benefits of recommendations for students, foundation preparation, business specialists and visionaries. Endless recommendations for students, foundation prep, specialists and business visionaries. One of the fundamental wellsprings of the proposed model is its high materialism to any situation where there is an instructive organization that trains understudies in abilities valuable for the work market. The research being undertaken also opens up the possibility to continue investigating major Blockchain innovations in different parts of the training and extrapolating the thinking introduced in this report to other application areas such as clinical analysis, monetary hazards or board information business, different organizations.

\section{References}

[1] F. P. Oganda, N. Lutfiani, Q. Aini, U. Rahardja, and A. Faturahman, "Blockchain Education Smart Courses of Massive Online Open Course Using Business Model Canvas," in 2020 2nd International Conference on Cybernetics and Intelligent System (ICORIS), 2020, pp. $1-6$.

[2] U. Rahardja, N. Lutfiani, A. S. Rafika, and E. P. Harahap, "Determinants of Lecturer Performance to Enhance Accreditation in Higher Education," in 2020 8th International Conference on Cyber and IT Service Management (CITSM), 2020, pp. 1-7.

[3] D. Apriani, A. Williams, U. Rahardja, A. Khoirunisa, and S. Avionita, "The Use of Science Technology In Islamic Practices and Rules In The Past Now and The Future," Int. J. Cyber IT Serv. Manag., vol. 1, no. 1, pp. 48-64, 2021.

[4] M. Kamil, U. Rahardja, P. A. Sunarya, Q. Aini, and N. P. L. Santoso, "Socio-Economic Perspective: Mitigate Covid-19 Impact on Education," in 2020 Fifth International Conference on Informatics and Computing (ICIC), 2020, pp. 1-7.

[5] Sudaryono, U. Rahardja, and N. Lutfiani, "The Strategy of Improving Project Management Using Indicator Measurement Factor Analysis (IMF) Method," in Journal of Physics: Conference Series, 2020, vol. 1477, no. 3, doi: 10.1088/1742-6596/1477/3/032023.

[6] M. Hardini, Q. Aini, U. Rahardja, R. D. Izzaty, and A. Faturahman, "Ontology of Education Using Blockchain: Time Based Protocol,” 2020, doi: 10.1109/ICORIS50180.2020.9320807.

[7] Q. Aini, M. Yusup, N. P. L. Santoso, A. R. Ramdani, and U. Rahardja, "Digitalization Online Exam Cards in the Era of Disruption 5.0 using the DevOps Method," J. Educ. Sci. Technol., vol. 7, no. 1, pp. 67-75, 2021.

[8] I. Faridah, F. R. Sari, T. Wahyuningsih, F. P. Oganda, and U. Rahardja, "Effect Digital Learning on Student Motivation during Covid-19," in 2020 8th International Conference on Cyber and IT Service Management (CITSM), 2020, pp. 1-5.

[9] L. Tarigan, P. Naibaho, and T. Siringo, "The Influence of Cultural And Christianity ValuesToward The Society," in Conference Series, 2020, vol. 2, no. 1, pp. 103-109.

[10] U. Rahardja, C. Lukita, F. Andriyani, and Masaeni, "Optimization of marketing workforce scheduling using metaheuristic genetic algorithms," Int. J. Adv. Trends Comput. Sci. Eng., vol. 9, no. 1.2 Special Issue, pp. 243-249, 2020, doi: 10.30534/IJATCSE/2020/3691.22020.

[11] Y. K. Susanta, "Trinitarian Missiology As An Effort to Establish Interfaith Dialogue and Relation in Indonesia," in Conference Series, 2020, vol. 2, no. 1, pp. 98-102.

[12] J. Leonard, D. Damanik, and O. Amirkhasanah, "Application of Information Session Information System as Media Submission of Final Results Comprehensive Session," J. Recent Innov., vol. 1, no. 1, pp. 62-70, 2020. 
[13] R. Lumbantobing, "The Impacts of Parental Communication for adolescence at Tarutung District, North Sumatra Indonesia," in Conference Series, 2020, vol. 2, no. 1, pp. 2328.

[14] P. A. Sunarya, U. Rahardja, L. Sunarya, and M. Hardini, "The Role Of Blockchain As A Security Support For Student Profiles In Technology Education Systems," InfoTekJar J. Nas. Inform. dan Teknol. Jar., vol. 4, no. 2, pp. 13-17, 2020.

[15] I. Handayani, D. Supriyanti, G. Maulani, and N. Lutfiani, "The ilearning journal center: Education startup to enhance lecturer research," Int. J. Adv. Trends Comput. Sci. Eng., vol. 9, no. 4, pp. 4678-4682, 2020, doi: 10.30534/ijatcse/2020/70942020.

[16] R. Simbolon, "The Influence of Micro Teaching Implementation for The Field Practicing Students of IAKN Tarutung," in Conference Series, 2020, vol. 2, no. 1, pp. 29-34.

[17] M. Almazrooie, A. Samsudin, A. A.-A. Gutub, M. S. Salleh, M. A. Omar, and S. A. Hassan, "Integrity verification for digital Holy Quran verses using cryptographic hash function and compression," J. King Saud Univ. Inf. Sci., vol. 32, no. 1, pp. 24-34, 2020.

[18] P. Dwiharyono, "Strategic Marketing for Indonesia Local Game Company To Increase Product Attractiveness," Available SSRN 3560600, 2020.

[19] Sudaryono, U. Rahardja, Q. Aini, Y. Isma Graha, and N. Lutfiani, "Validity of Test Instruments," J. Phys. Conf. Ser., vol. 1364, no. 1, 2019, doi: 10.1088/1742$6596 / 1364 / 1 / 012050$.

[20] H. Kornelius, I. Bernarto, and A. W. Widjaja, "Crafting Strategic Maneuverability to Boost Business Performance," in Conference Series, 2020, vol. 3, no. 1, pp. 754-768.

[21] Y. Xu and Y. Huang, "Segment blockchain: A size reduced storage mechanism for blockchain," IEEE Access, vol. 8, pp. 17434-17441, 2020.

[22] T. Hewa, M. Ylianttila, and M. Liyanage, "Survey on blockchain based smart contracts: applications, opportunities and challenges," J. Netw. Comput. Appl., p. 102857, 2020.

[23] N. K. Dumpeti and R. Kavuri, "A framework to manage smart educational certificates and thwart forgery on a permissioned blockchain," Mater. Today Proc., 2021.

[24] Gunawan, I. K., Sukmana, H. T., \& Ardianto, A. Y. (2021). Blockchain Technology as A Media for Sharing Information that Generates User Access Rights and Incentives. Blockchain Frontier Technology, 1(01), 44-55.

[25] Upreti, M., Hardini, M., Rahmania, R., \& Abianto, C. (2021). Blockchain Based Registration Model for Higher Education. Blockchain Frontier Technology, 1(01), 68-73. 